\title{
The Effect of Heat Treatment on Microstructure, Microhardness and Pitting Corrosion of Ti6Al4V Produced by Electron Beam Melting Additive Manufacturing Process
}

\author{
Mingzhen Xiu \\ Nanyang Technological University https://orcid.org/0000-0003-0813-4217 \\ Yong Teck Tan \\ Nanyang Technological University \\ Srinivasan Raghavan \\ Nanyang Technological University \\ Min Hao Goh \\ Nanyang Technological University \\ Mui Ling Sharon Nai ( $\nabla$ mlnai@simtech.a-star.edu.sg ) \\ Nanyang Technological University
}

\section{Research Article}

Keywords: Electron beam melting, Ti6Al4V, microstructure control, heat treatment, $\beta$ phase, pitting potential

Posted Date: November 18th, 2021

DOI: https://doi.org/10.21203/rs.3.rs-1071502/v1

License: (c) (i) This work is licensed under a Creative Commons Attribution 4.0 International License. Read Full License

Version of Record: A version of this preprint was published at The International Journal of Advanced Manufacturing Technology on February 11th, 2022. See the published version at https://doi.org/10.1007/s00170-022-08839-4. 
The effect of heat treatment on microstructure, microhardness and pitting corrosion of Ti6Al4V produced by Electron Beam Melting additive manufacturing process

Mingzhen Xiu ${ }^{\mathrm{a}}$, Yong Teck Tan ${ }^{\mathrm{b}}$, Srinivasan Raghavan ${ }^{\mathrm{b}}$, Min Hao Goh ${ }^{\mathrm{b}}$, Mui Ling Sharon Naib,*

${ }^{a}$ Nanyang Technological University, School of Materials Science \& Engineering, 11

Faculty Ave, Singapore 639977

${ }^{\mathrm{b}}$ SIMTech - Singapore Institute of Manufacturing Technology, 73 Nanyang Drive, Singapore 637662

*Corresponding author.

E-mail address: mlnai@ simtech.a-star.edu.sg 


\section{Highlights}

- $\quad$ Microstructure of electron beam melting Ti6Al4V under 3 different heat treatment profiles were studied

- An increase in the $\alpha$ lath width results in the microhardness decreasing

- For pitting corrosion resistance, the $\beta$ phase fraction is a better indicator than the $\alpha$ lath width

- Solution air-cooled \& ageing heat treatment method improves both the microhardness and corrosion resistance

\section{$\underline{\text { Abstract }}$}

There has been limited studies on corrosion behaviour of post-processed Electron Beam Melted (EBM) Ti6Al4V, given that the factors affecting corrosion resistance of AM Ti6Al4V remain unclear. This paper proposes using heat treatment method to improve the pitting corrosion resistance of EBM Ti6Al4V. Different treatment profiles alter the microstructure of EBM Ti6Al4V. A clear trend is observed between microhardness and $\alpha$ lath width. As-printed EBM Ti6Al4V exhibits an inferior pitting potential, while heat treatment provided a significant improvement in the corrosion resistance. This study finds that the $\beta$ phase fraction is a better indicator than the $\alpha$ lath width for pitting corrosion resistance. Solution air-cooled \& ageing heat treated EBM Ti6Al4V exhibits good mechanical and corrosion properties, and even performs better than commercial cast Ti6Al4V.

Keywords: Electron beam melting, Ti6Al4V, microstructure control, heat treatment, $\beta$ phase, pitting potential 


\section{Introduction}

Additive manufacturing (AM) is an attractive and effective manufacturing technique used in producing complex components or prototypes. AM has multiple advantages over conventional manufacturing methods such as less waste, assembly-free, simple processing steps, and rapid manufacturing for highly complex components. AM is able to produce near-net shape 3D components by using thermal energy to melt metal powders, thus achieving layer-wise printing from sliced 3D CAD model data $[1,2]$. However, AM processing has a shortcoming of rapid inherent directional solidification, leading to highly non-equilibrium microstructure of the as-printed metal part [3]. Such unique solidification process gives that the formation of martensite phase and columnar grains in titanium alloys $[2,4,5]$. Electron beam melting (EBM) is a representative technique of powder-bed fusion metal AM technology, and was selected to build titanium alloy samples in this study. EBM generates a high energy electron beam from a tungsten filament electron gun which can accelerate to $60 \mathrm{kV}$ and selectively melt the titanium powders. It operates in a controlled vacuum $\left(\sim 2 \times 10^{-3}\right.$ mbar) and elevated temperature condition to avoid oxidation and internal pressure during processing. Hence EBM is always used to fabricate near net shape metal parts. EBM parts can be found in multiple applications in orthopaedic [6], aeronautics, and motorsports [7], with the mechanical behaviour of as-printed EBM metal parts comparable or even better than traditional processed metal parts $[4,8]$.

There are numerous studies on the relationship between EBM process parameters and microstructure of Ti6Al4V alloy. The effect of the main processing parameters including beam current, focus offset, speed function, reference length, line offset, and average currents on the microstructure of EBM Ti6Al4V were investigated [9]. The variation in as-printed EBM Ti6Al4V microstructure as a function of building height was reported [10-12], an increase of $\alpha$ lath width was detected with increasing building height, and a transformation from coarse to fine microstructure was detected from bottom to top parts of EBM Ti6Al4V metal alloy. Sun et al. had discussed the effect of building direction on the microstructure of EBM as-printed metal alloy [13]. The mechanical properties including yield stress, elastic modulus, tensile strength, and elongation for as-printed EBM Ti6Al4V have been well studied [13, 14]. A decrease in the mechanical properties was observed by increasing building temperature which is associated with microstructural coarsening. Toh and Murr et al. reported fine microstructure introducing higher microhardness to EBM Ti6Al4V that was comparable to the as-cast and as-wrought, and higher wear resistance was also observed $[15,16]$. The particles size effect on the microstructure and the mechanical properties of EBM Ti6Al4V was elucidated [17], the hot isostatic press (HIP) was reported to improve fatigue strength, porosity, and ductility. Some studies have been conducted on the variation in the microstructure and mechanical properties of EBM Ti6Al4V induced by post process heat treatment $[2,4,18,19]$. Surprisingly, there was no significant improvement in the mechanical properties of EBM Ti6Al4V in recent literature $[2,4,18]$, and there are only a few studies on post heat treatment of EBM Ti6Al4V. However, the heat treatment was necessary for selective laser melting (SLM) Ti6Al4V due to the high internal thermal stress [20]. 
To the best of our knowledge, there is a very limited investigation on the corrosion properties of AM Ti6A14V alloy, especially for EBM processing. The corrosion resistance of different building planes of SLM Ti6Al4V was reported by Dai Nianwei [21], XY-plane had a better corrosion resistance due to the presence of more $\alpha^{\prime}$ martensite and less $\beta$ phase. Dai Nianwei had also investigated the relationship between the $\beta$ phase percentage and the corrosion resistance of SLM Ti6Al4V in [22], the as-printed SLM Ti6Al4V had a worse corrosion resistance than commercial grade 5 samples due to the lower amount of $\beta$ phase percentage. The corrosion behaviour of EBM Ti6Al4V with different building directions had been investigated in the $\mathrm{HCl}$ solution, building direction with $0^{\circ}$ had the best corrosion resistance due to the lower $\beta$ phase percentage [23].

In contrast to the above published studies, Bai Jun et al. reported that slightly better electrochemical corrosion behaviour of EBM as-printed Ti6Al4V was observed compared to wrought counterpart due to the presence of a higher fraction of $\beta$ phase [24]. Likewise, the development of the $\beta$ phase by post-annealing treatment leading to improvement of corrosion resistance of the direct metal laser sintered (DMLS) asprinted Ti6Al4V was published by Xu Yangzi et al. [25]. Hence, the effect of $\beta$ phase percentage on corrosion resistance of Ti6Al4V remains unresolved within the field of AM Ti6Al4V.

Similarly, Yang et al. reported the heat treated SLM Ti6Al4V showed comparable corrosion behaviours to the conventional rolling Ti6Al4V in $\mathrm{NaCl}$ solution due to the combined effects of microstructures [26]. Whereas Abdeen et al. proved the as-printed EBM Ti6Al4V had comparable pitting potential to wrought Ti6Al4V alloy in $\mathrm{NaCl}$ solution at the temperature of $80{ }^{\circ} \mathrm{C}$ [27]. While Gai et al. elucidated the passive film formed on EBM Ti6Al4V surface was the key contributing factor to the corrosion resistance [28]. Hence, there is a need for a systematic study regarding EBM Ti6A14V corrosion resistance properties and the key factors affecting the corrosion resistance.

Although Ti6Al4V is resistant towards most chloride-containing solutions [29], but it is more susceptible to the bromide-containing solution [30-33], which can cause a localized breakdown of titanium passive oxide film due to pitting corrosion. Since post processing heat treatment for EBM printed metal alloy is a promising technique to alter microstructure as well as improving mechanical properties [2, 4, 18, 19], this work aims to measure the pitting corrosion resistance in $\mathrm{NaBr}$ solution, and understand the correlation of microhardness and pitting potential associated with microstructure arising from three different post processing heat treatments. The study shows the asprinted EBM Ti6Al4V exhibits inferior corrosion resistance, the best heat treatment profile is identified that offers the best mechanical and corrosion properties. While the traditional wrought and cast Ti6Al4V alloys were used as benchmarks in this study. 


\section{Experimental details}

\subsection{As printed EBM Ti6Al4V cubic block fabrication}

Arcam A2X Electron Beam Melting machine was used to fabricate the solid electron beam melting (EBM) Ti6Al4V alloy parts. The pre-alloyed grade 5 Ti6Al4V powders were purchased from Arcam AB. The powders had a near-spherical shape with a mean particle size of $61.8 \mu \mathrm{m}$ and a distribution range from $45 \mu \mathrm{m}$ to $105 \mu \mathrm{m}$, the elemental composition is given in Table 1 [8, 12]. An EBM Ti6Al4V cubic block with dimensions of $30 \times 30 \times 30 \mathrm{~mm}$ was fabricated on a stainless steel start plate. The operating condition for the EBM machine was under the vacuum pressure $<1 \times 10^{-4}$ mbar, $3000 \mathrm{~W}$ beam power, and STL CAD interface.

\section{Table 1}

Elemental composition of grade 5 Ti6Al4V powder $[8,12]$

\begin{tabular}{ccccccccc}
\hline Element & $\mathbf{C}$ & $\mathbf{F e}$ & $\mathbf{N}_{2}$ & $\mathbf{O}_{2}$ & $\mathbf{A l}$ & $\mathbf{V}$ & $\mathbf{H}_{2}$ & $\mathbf{T i}$ \\
\hline $\begin{array}{c}\text { Content } \\
(\%)\end{array}$ & $<0.1$ & $<0.3$ & $<0.05$ & $<0.2$ & $5.5 \sim 6.75$ & $3.5 \sim 4.5$ & $<0.015$ & Balance \\
\hline
\end{tabular}

\subsection{Post processing}

The as-printed sample was sliced along the $\mathrm{X}$-Y plane into four identical pieces $(30 \times$ $30 \times 7 \mathrm{~mm}$ ). The heat treatment was conducted in a vacuum furnace. Since the transformation from $\alpha+\beta$ to $\beta$ phase occurs near to $995^{\circ} \mathrm{C} \sim 1000{ }^{\circ} \mathrm{C}$ according to the phase diagram of Ti6Al4V , sub $\beta$-transus is the temperature region below the critical temperature whereas super $\beta$-transus is above the critical temperature [2]. The heat treatment profiles in this study were selected in those two regions, the details are listed in Table 2.

Table 2

Heat treatment profiles of Ti6Al4V samples

\begin{tabular}{cccc}
\hline Sample & Heating Temperature $\left({ }^{\circ} \mathbf{C}\right)$ & Heating time $(\mathbf{h})$ & Cooldown \\
\hline Sub $\boldsymbol{\beta}$-transus & 950 & 3 & Furnace \\
\hline Super $\boldsymbol{\beta}$-transus & 1050 & 2 & Furnace \\
\hline Solution Air-cooled \& & 1050 & 2 & Air \\
Ageing (SAA) & 500 & 8 & Furnace \\
\hline
\end{tabular}

All samples including cast and wrought were grounded and polished to a mirror finishing by using a Struers Sample Preparation System before microstructural observation, electrochemical corrosion test, and microhardness test. The samples were first mounted with polyfast resin by Citopress hot mounting machine, then grounded with grit SiC paper from grade P320 to P4000, followed by polishing to mirror finishing using a MD Chem magnetic polishing cloth with $0.05 \mu \mathrm{m}$ oxide polishing diamond suspension and lubricant. 


\subsection{Surface characterization}

The mirror finish samples were etched using Kroll's reagent (2\% $\mathrm{HF}, 4 \% \mathrm{HNO}_{3}, 94 \%$ $\mathrm{H}_{2} \mathrm{O}$ ) for microstructure observation. The surface morphology images were obtained by Olympus GX51 optical microscope and JEOL Scanning Electron Microscope (SEM) 5410. The phases fraction and the $\alpha$ lath width were measured by Image $\mathbf{J}$ software. The surface oxide layer profile was investigated by X-ray photoelectron spectroscopy (Thermo Scientific ESCALAB 250Xi) with monochromatic Al Ka radiation of $900 \mu \mathrm{m}$ spot size. Processing of XPS results was carried out by Thermo Scientific Advantage software. The microhardness value was determined on the mirror finish samples under ambient conditions through a Vickers hardness tester (HV) as per ASTM E92 standard, loading with $300 \mathrm{gf}(2.94 \mathrm{~N})$ and $15 \mathrm{~s}$ dwell time.

\subsection{Electrochemical measurement}

Electrochemical characterization of the samples was carried out using an Applied Corrosion Monitoring (ACM) Field Machine potentiostat under ambient conditions $\left(\sim 25^{\circ} \mathrm{C}\right)$. A three-electrodes electrochemical cell was used with graphite rod counter electrode and SCE reference electrode, the working electrode was post processed EBM Ti6Al4V samples with $1 \mathrm{~cm}^{2}$ exposed area. The electrolyte was $1 \mathrm{M}$ sodium bromide $(\mathrm{NaBr})$ solution, prepared by mixing reagent grade $\mathrm{NaBr}$ powder (GCE Laboratory Chemicals) and $100 \mathrm{ml}$ de-ionized water. The electrochemical characterization was done by cyclic polarization test, and the potential cycle between $-1 \mathrm{~V}$ to $+3 \mathrm{~V}$ vs. SCE was applied with a sweep rate of $1 \mathrm{mV} / \mathrm{s}$.

\section{Results}

\subsection{Microstructure}

For the microstructure of as-printed electron beam melting (EBM) Ti6Al4V, an equiaxed shape of prior $\beta$ grains is observed on the X-Y plane as shown in Fig. 1(a), while the columnar prior $\beta$ grains with a very fine $\alpha+\beta$ lamellar pattern is found on the $\mathrm{Z}$ plane in Fig. 1(b). The SEM image (Fig. 1(c)) presents a lamellar phases microstructure that the dark background is $\alpha$ phase and the bright strip is $\beta$ phase, it is a typical as-printed EBM Ti6Al4V microstructure pattern [34]. $\alpha$ lath is identified as the spacing between the two bright $\beta$ phases that is an important factor to determine the mechanical properties of EBM Ti6Al4V. The effect of $\alpha$ lath on microhardness and corrosion resistance will be discussed in later sections.
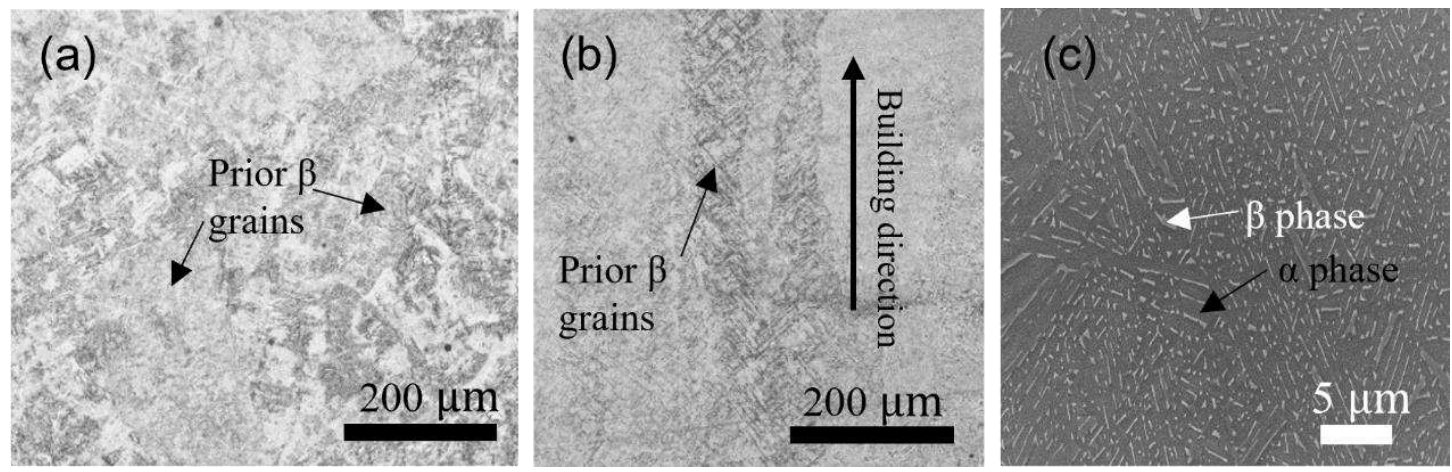

Fig. 1 Microstructure of as-printed EBM Ti6Al4V: (a) optical image of X-Y plane, (b) optical image of Z plane, (c) SEM images of X-Y plane 
The sub $\beta$-transus specimen was obtained through heating at a temperature of $950{ }^{\circ} \mathrm{C}$ ( $\beta$-transus region) for three hours and gradually cooled down to room temperature in the furnace. The microstructure is similar to as printed EBM Ti6Al4V. Fig. 2(a) shows the equiaxed shape prior $\beta$ grains on the $X-Y$ plane, while the columnar prior $\beta$ grains on the $\mathrm{Z}$ plane are observerd in Fig. 2(b). Semiatin et al. reported that the $\beta$ phase fraction would be increased from $4 \%$ to $75 \%$ in the region of $\beta$-transus [35]. Since the $\alpha$ phase will not completely transform into the $\beta$ phase below the transus temperature according to the phase diagram, the presence of the $\alpha$ phase will hinder the growth of $\beta$ grains given that the columnar morphology remains unchanged in the sub $\beta$-transus heat treatment. However, the coarsening of width and length of both $\alpha$ and $\beta$ phase are seen from the SEM image (Fig. 2(c)).
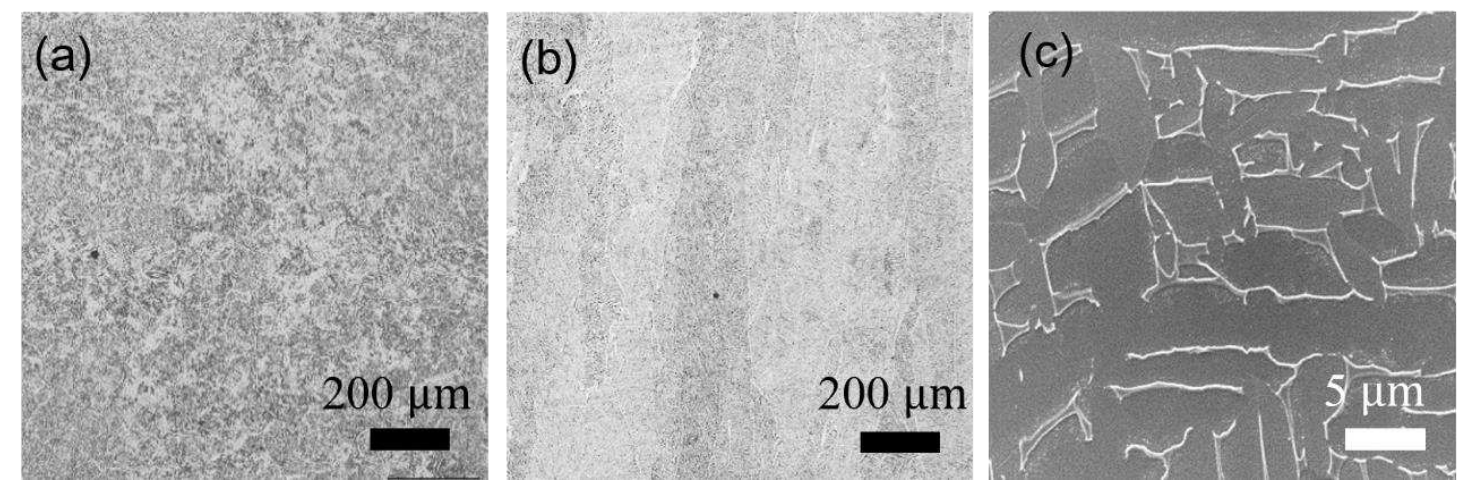

Fig. 2 Microstructure of sub $\beta$-transus Ti6Al4V: (a) optical image of X-Y plane, (b) optical image of $\mathrm{Z}$ plane, (c) SEM images of $\mathrm{X}$-Y plane

In the super $\beta$-transus heat treatment, the specimen was heated up to $1050{ }^{\circ} \mathrm{C}$ for 2 hours and gradually cooled down in the furnace to room temperature. At $1050{ }^{\circ} \mathrm{C}$, the $\alpha$ phase is completely transformed into $\beta$ phase based on the phase diagram, while the $\alpha$ phase will be re-precipitated upon the cooling process. The precipitation is mainly affected by cooling rate and temperature. Morphology transformation of the grains from the columnar to the equiaxed can be observed in Fig. 3 (a) and (b). The SEM image (Fig. 3 (c)) shows the further growth of the $\beta$ phase and coarsening of the $\alpha$ lath. The $\beta$ phase exhibits a more organised and directional pattern comparing to the intermittent $\beta$ phase in as-printed or sub $\beta$-transus specimens.
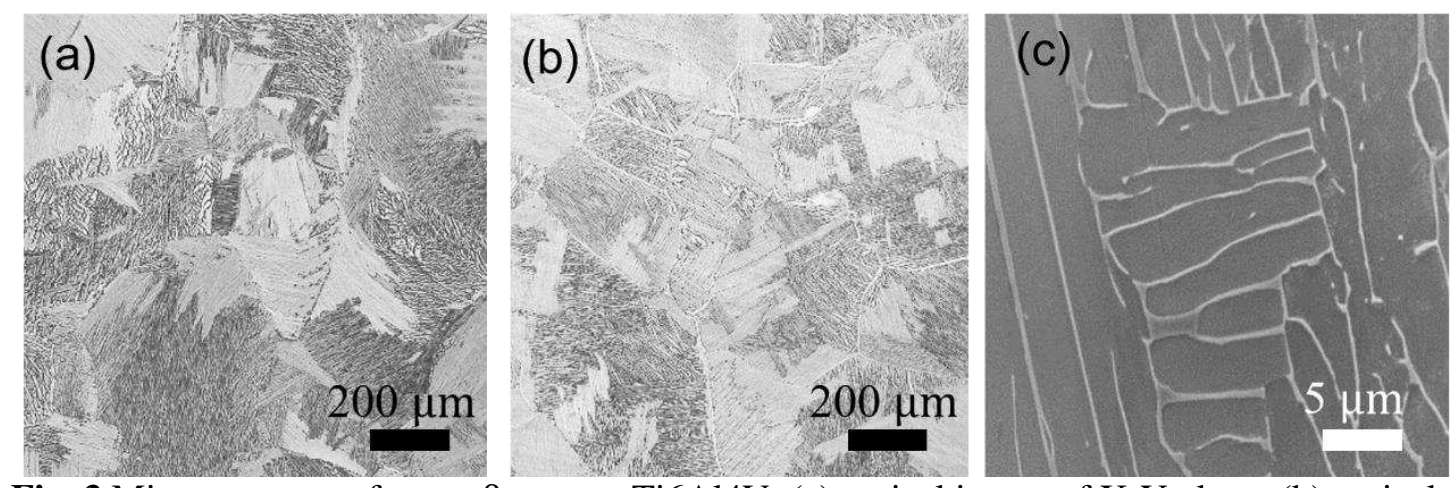

Fig. 3 Microstructure of super $\beta$-transus Ti6Al4V: (a) optical image of X-Y plane, (b) optical image of Z plane, (c) SEM images of X-Y plane 
A Widmanstätten microstructure is obtained in solution air-cooled \& ageing (SAA) heat treatment. In the first part of heat treatment, the specimen was heated up to $1050{ }^{\circ} \mathrm{C}$ where the grain the morphology was transformed from columnar to the equiaxed structure, as can be seen in Fig. 4(a) and 4(b). The grain structure is very similar to that of a super $\beta$-transus specimen. A very fine Widmanstätten structure pattern is found inside the large grains, as shown in Fig. 4(c). It is formed through the rapid cooling process. The structure exhibits highly orientated and tightly packed $\alpha+\beta$ lamellar phases, the precipitation of $\beta$ phases is also clearly revealed. The $\alpha$ lath width is much narrower compared to the other two heat treatments methods.
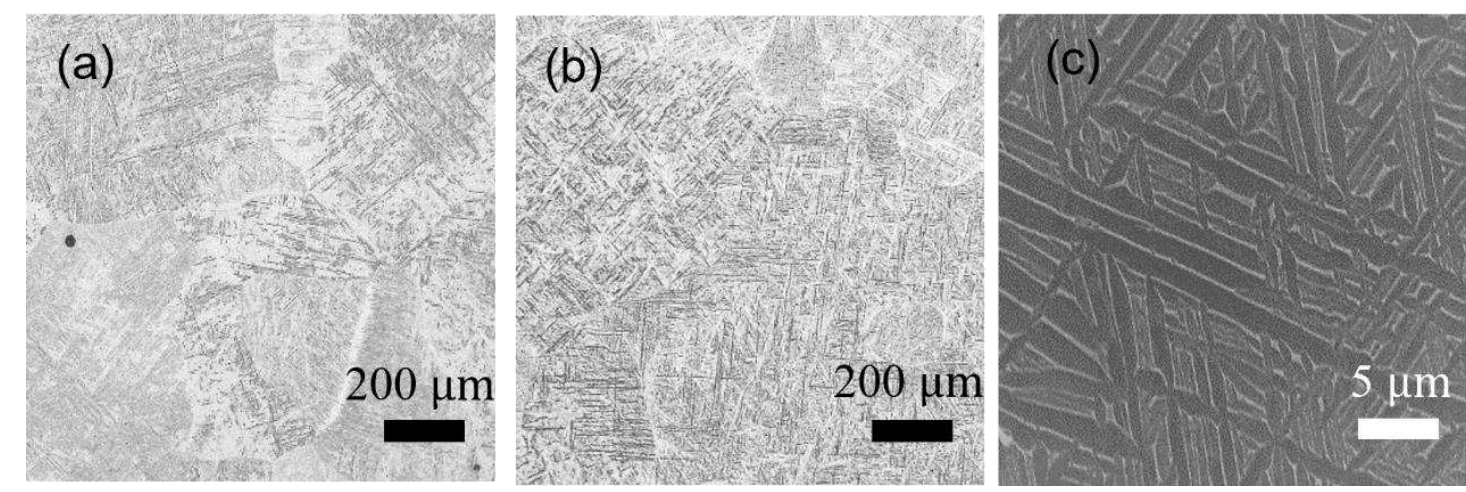

Fig. 4 Microstructure of solution Air-cooled \& Ageing (SAA) Ti6Al4V: (a) optical image of $\mathrm{X}-\mathrm{Y}$ plane, (b) optical image of Z plane, (c) SEM images of X-Y plane

\section{$3.2 \alpha$ lath width and microhardness}

The $\alpha$ lath width is the distance between two $\beta$ phases, was measured and plotted in Fig. 5 (a). The as-printed specimen has the narrowest average $\alpha$ lath width $(\sim 0.55 \mu \mathrm{m})$ among all the EBM specimens. An upward trend is seen among as-printed, sub $\beta$ transus $\left(950{ }^{\circ} \mathrm{C}\right)$ and super $\beta$-transus $\left(1050{ }^{\circ} \mathrm{C}\right)$ specimens with the same cooling method. The super $\beta$-transus specimen with $2.36 \mu \mathrm{m} \alpha$ lath width has the coarsest microstructure in the present study, which indicates that the wider $\alpha$ lath width the higher heating temperature. Although the solution air-cooled \& ageing (SAA) specimen was also processed with a high heating temperature, it had a very fine average $\alpha$ lath width $(\sim 0.8 \mu \mathrm{m})$ due to the rapid cooling rate. $\alpha$ lath for both cast and wrought samples is not measurable because no $\alpha+\beta$ lamellar structure is observed. Microhardness testing was conducted on the mirror surface along the X-Y plane of each specimen. Different measurement sites on each sample's surface are recorded and plotted in Fig. 5 (b). Among all the specimens, conventional cast specimen has the lowest microhardness value ( 296.8 HV), whereas as-printed EBM specimen has the highest microhardness value $(\sim 360.3 \mathrm{HV})$, given that the finest $\alpha$ lath width leading to the best mechanical properties. The average microhardness values for all EBM specimens are higher than that of the cast specimen and also, with the exception of the super $\beta$-transus, higher than the wrought specimen. 

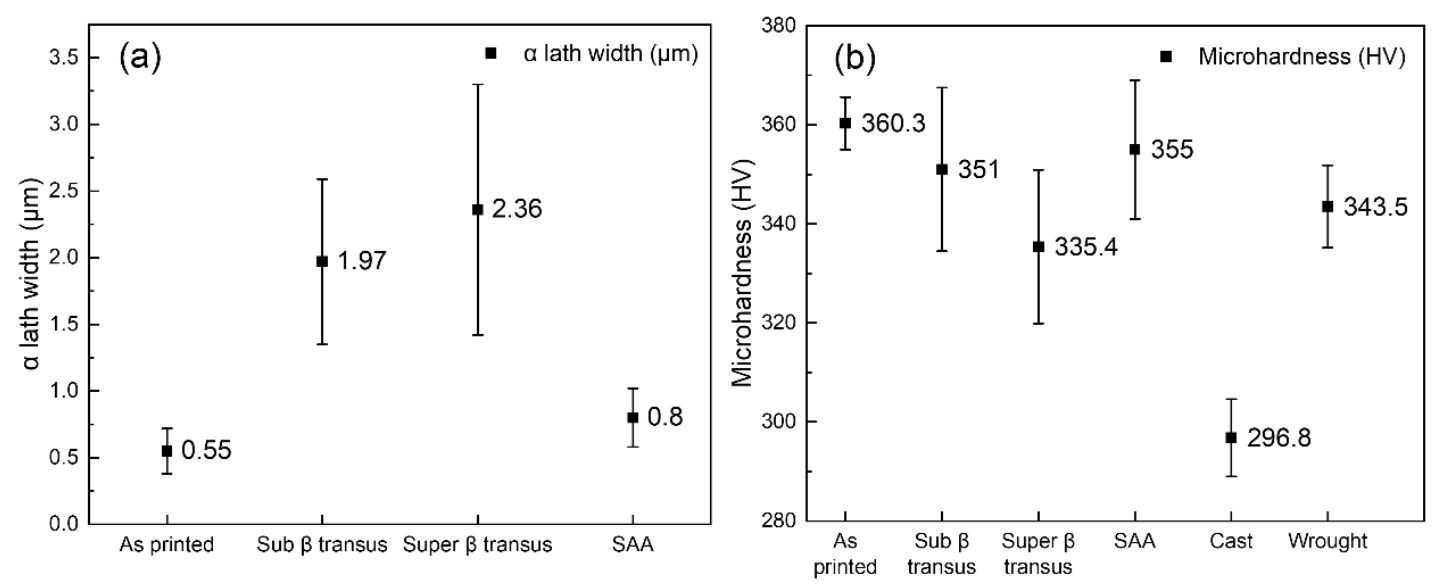

Fig. 5 (a) average of $\alpha$ lath width, and (b) average microhardness value for EBM and traditional processed Ti6Al4V

\section{$3.3 \beta$ phase fraction}

Fig. 6 presents the quantification of the $\beta$ phase for each specimen. The as-printed EBM specimen has the lowest average $\beta$ phase fraction of $6.4 \%$ because of the high amount of aluminium ( $\alpha$ stabilizer) [36]. There is an upward trend within EBM specimens, and also a significant increase in $\beta$ phase fraction for all heat treated specimens are observed. It indicates that the higher $\beta$ phase fraction can be obtained by increasing heat treatment temperature. The highest value of $9.9 \%$ is from the SAA specimen, which may be due to the $\beta$ phase precipitation during ageing process. In contrast to the traditional cast and the wrought Ti6Al4V, only the super $\beta$-transus and the SAA specimens have a higher amount of $\beta$ fraction.

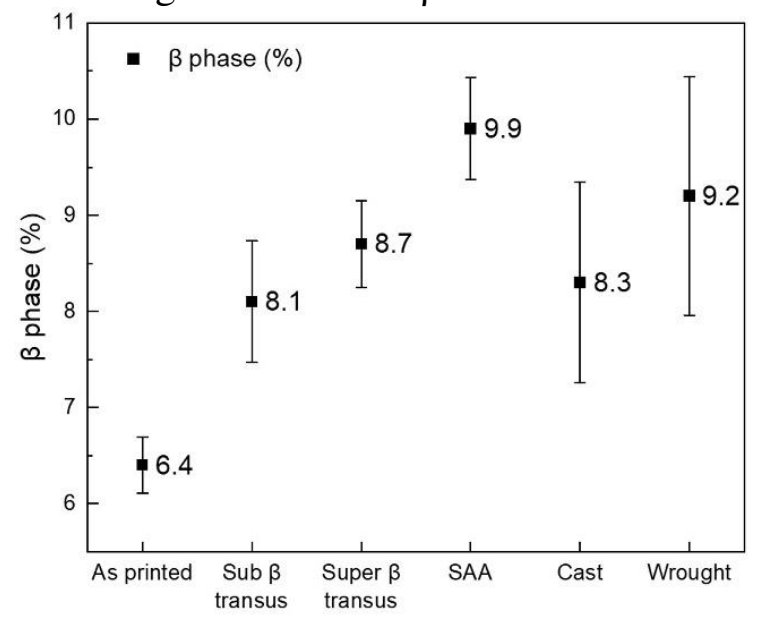

Fig. $6 \beta$ phase fraction for EBM and traditional processing Ti6Al4V

\subsection{SEM-EDS results}

To further investigate the $\alpha$ and the $\beta$ phases of EBM Ti6Al4V, SEM-EDS was carried out on a super $\beta$-transus specimen. The SEM-EDS spectra and quantitative composition data are displayed in Fig. 7 and Table 3, respectively. The Fig. 7 (a) and (b) compares the peak position and intensity for $\alpha$ and $\beta$ phases, given that they are having the same elemental composition (carbon, aluminum, vanadium, titanium, and iron). Table 3 presents that the $\beta$ phase has higher amount of vanadium $(7.67 \%)$ and iron $(0.6 \%)$ elements, while the $\alpha$ phase contains more aluminum (3.56\%). This finding is consistent with Kuma et al. [37] who found that vanadium and iron are the $\beta$ phase stabilizer whereas 
aluminum is the $\alpha$ phase stabilizer. The effect of vanadium on corrosion resistance will be discussed.
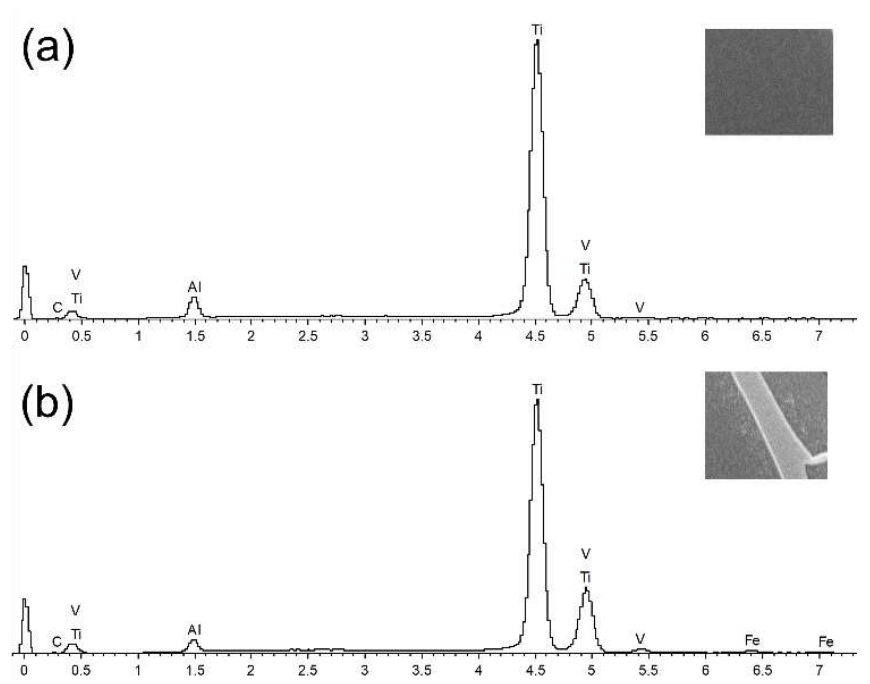

Fig. 7 SEM-EDS spectra of EBM Ti6Al4V: (a) $\alpha$ phase, and (b) $\beta$ phase

Table 3

The elemental composition of Ti6Al4V

\begin{tabular}{cccccc}
\hline Element & $\mathbf{C}$ & $\mathbf{A l}$ & $\mathbf{T i}$ & $\mathbf{V}$ & $\mathbf{F e}$ \\
\hline $\boldsymbol{\alpha}$ phase content $(\boldsymbol{\%})$ & $0.77 \pm 0.12$ & $3.56 \pm 0.14$ & $93.31 \pm 0.39$ & $2.36 \pm 0.47$ & Negligible \\
\hline $\boldsymbol{\beta}$ phase content $(\boldsymbol{\%})$ & $0.79 \pm 0.15$ & $2.66 \pm 0.35$ & $88.42 \pm 1.84$ & $7.67 \pm 1.85$ & $0.6 \pm 0.08$ \\
\hline
\end{tabular}

\subsection{XPS result}

Fig. 8 presents the XPS results of as-printed, sub $\beta$-transus, and wrought specimens. The Ti $2 p$ peaks are observed in Fig. 8 (a), the Ti(IV) $2 p_{1 / 2}$ and Ti(IV) $2 p_{3 / 2}$ core level peaks have the binding energy of $464.18 \mathrm{eV}$ and $458.38 \mathrm{eV}$ respectively with $5.8 \mathrm{eV}$ splitting, whereas the peak at $456.08 \mathrm{eV}$ is assigned to $\mathrm{Ti}(0)$. The Ti $2 \mathrm{p}$ spectrum profiles of the three specimens are consistent, with insignificant difference in peak position and intensity. The oxide film thickness of the native air-formed oxide film is calculated and shown in Fig. 8 (b). The as-printed, sub $\beta$-transus, and wrought specimens have calculated oxide thickness of $5.4 \mathrm{~nm}, 5.5 \mathrm{~nm}$, and $5.2 \mathrm{~nm}$, indicating that there is no significant difference in oxide thickness across the various samples.

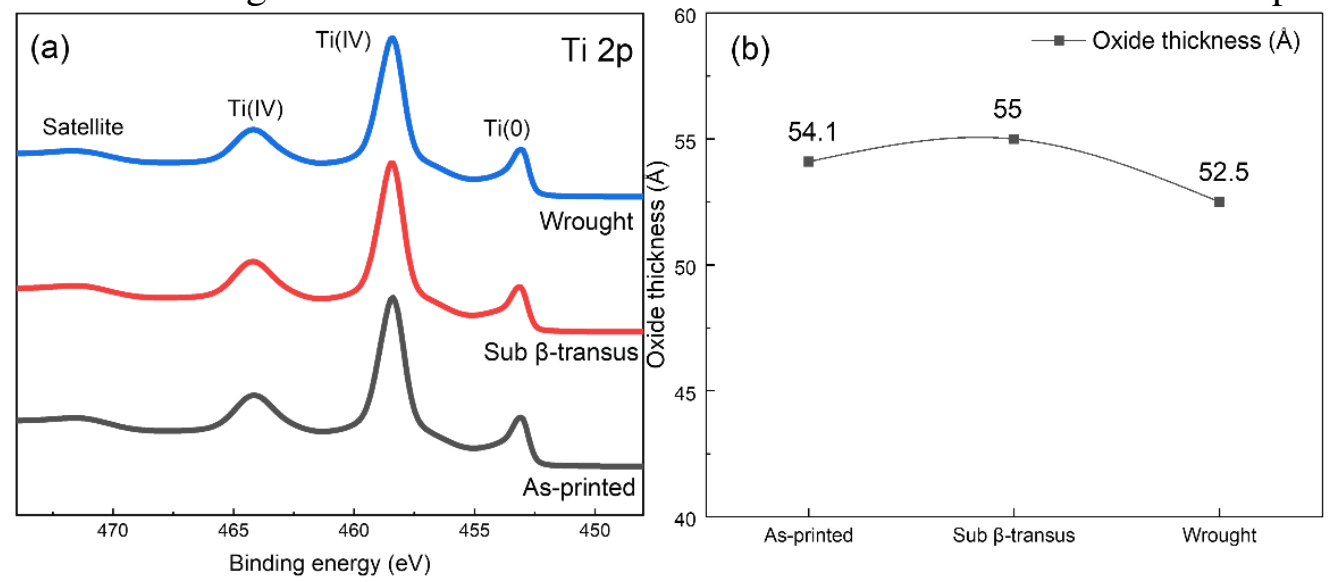

Fig. 8 XPS spectra of (a) Ti 2p region, and (b) dioxide thickness 


\subsection{Electrochemical study}

The cyclic polarization measurements were performed in $1 \mathrm{M} \mathrm{NaBr}$ solution, as shown in Fig. 9. The pitting potential $\left(E_{\mathrm{p}}, \mathrm{mV}\right)$ are summarized in Table 4 . The polarization curves exhibit a passivation behaviour and good reproducibility. Since the lower the passivation current density, the better the corrosion resistance of the metal in the passive region. However, the passivation current density of all the specimens was in the range of $4 \sim 5 \mu \mathrm{A} / \mathrm{cm}-2$, given that no significant difference across the various samples is observed. The pitting potential $\left(E_{\mathrm{p}}\right)$ is the potential above which an initiated pit can propagate indefinitely, leading to a state of stable pitting, and is a measure of the stability of the passive film. When the potential is above the $E_{\mathrm{p}}$, pitting corrosion will occur and the current will increase rapidly. The more positive the $E_{\mathrm{p}}$, the better the resistance against pitting corrosion.

Among all the EBM Ti6Al4V specimens, as-printed specimen has the lowest pitting potential of $+1.61 \mathrm{~V}$ vs. SCE indicating the worst resistance towards pitting corrosion in this study. There is a significant increase in the pitting potential for post processed EBM Ti6Al4V. Sub $\beta$-transus ( +2.21 V vs. SCE), super $\beta$-transus $(\sim+2.17 \mathrm{~V}$ vs. SCE), and SAA $(\sim+2.21 \mathrm{~V}$ vs. SCE) have much higher pitting potentials as compared to asprinted specimen, given that the heat treatment is an effective way to greatly improve the stability of the passive film as well as the corrosion resistance. This finding is consistent with that of Xu Yangzi et al who reported as printed Ti6Al4V had inferior corrosion resistance and could be improved through heat treatment [25]. The comparison between EBM and traditional processed Ti6Al4V suggests that the post processed EBM specimens exhibit corrosion resistance comparable to wrought Ti6Al4V $(\sim+2.21 V$ vs. SCE $)$ and better than cast Ti6Al4V $(\sim+2.10 \mathrm{~V}$ vs. SCE $)$.
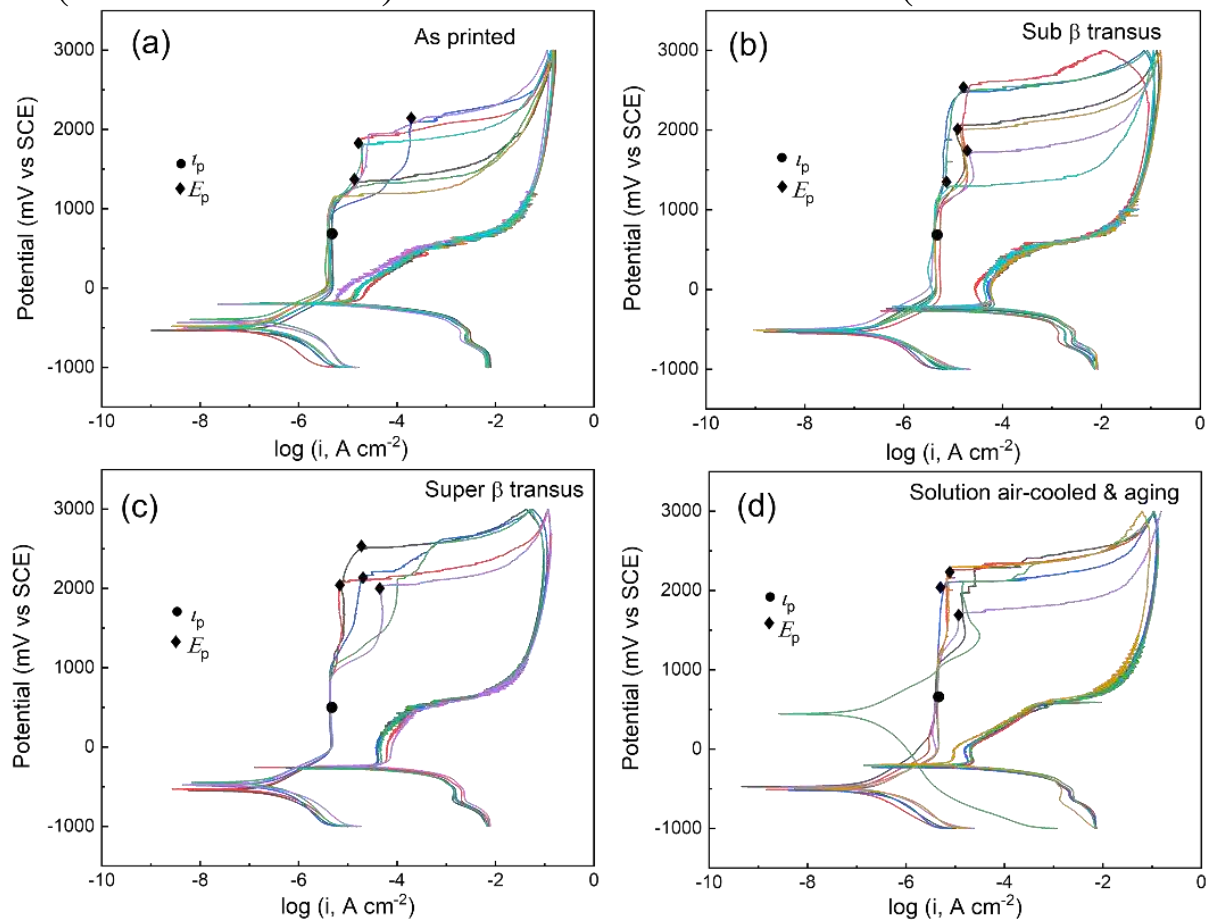

Fig. 9 Potentiodynamic polarization curves: (a) as-printed, (b) sub $\beta$-transus, (c) super $\beta$ transus and (d) Solution Air-cooled \& Ageing (SAA) immersed in1M NaBr solution 
Table 4

The electrochemical corrosion parameters for Ti6Al4V

\begin{tabular}{cc}
\hline Heat treatment & $\begin{array}{c}\text { Pitting potential } \\
(\boldsymbol{V} \text { vs. SCE })\end{array}$ \\
\hline As-printed & $1.61 \pm 0.41$ \\
\hline Cast & $2.10 \pm 0.38$ \\
\hline Super $\beta$-transus & $2.17 \pm 0.17$ \\
\hline Sub $\beta$-transus & $2.21 \pm 0.35$ \\
\hline Wrought & $2.21 \pm 0.35$ \\
\hline Solution Air-cooled \& & $2.21 \pm 0.92$ \\
Ageing (SAA)
\end{tabular}

Fig. 10 shows the optical microscope images of the EBM Ti6Al4V specimens after cyclic polarization measurement. The dark area is the specimen surface with $\sim 1 \mathrm{~cm}^{2}$ that was exposed to the aqueous solution. There are several large cavities (light colour region) on the specimen surface, they are deep in centre and shallow at the edges. The cavities are identified as pitting corrosion that is formed upon the complete cycle of potentiodynamic polarization test.

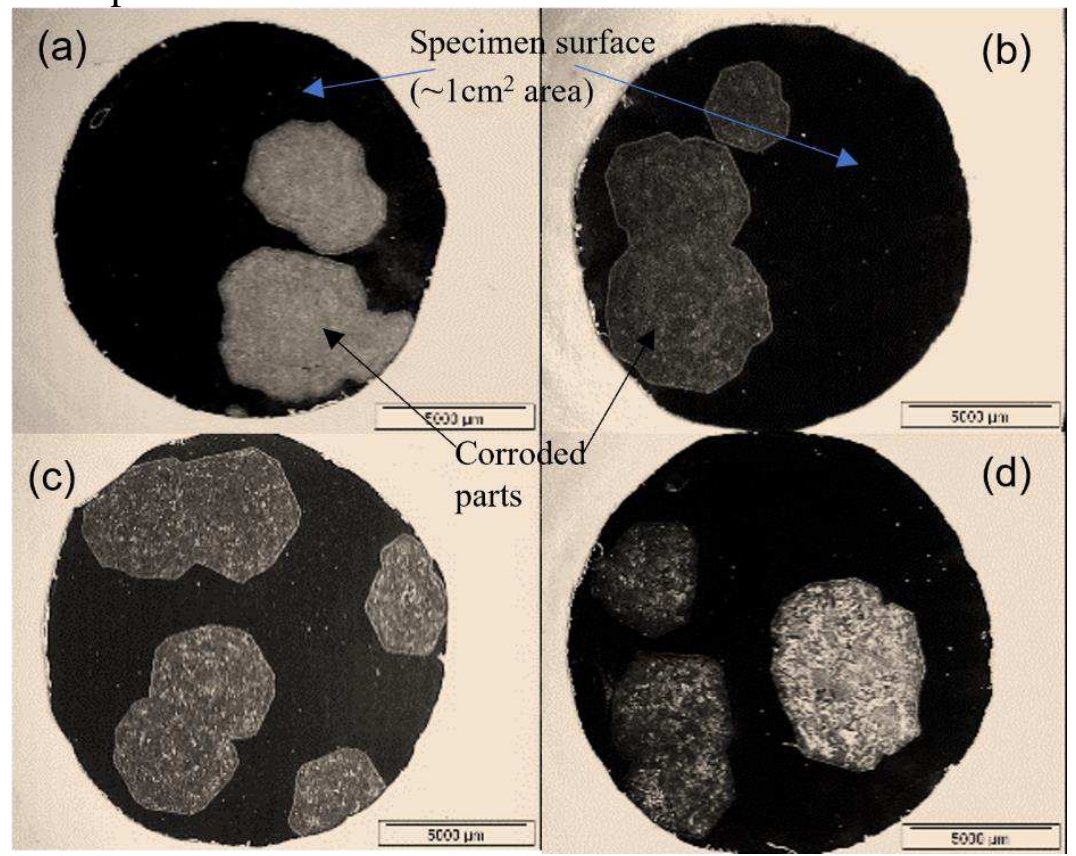

Fig. 10 Low magnification optical microscope images of corroded EBM Ti6Al4V specimen surface: (a) as-printed, (b) sub $\beta$-transus, (c) super $\beta$-transus, and (d) Solution Air-cooled \& Ageing (SAA)

To further investigate the corrosion behaviour on EBM Ti6Al4V, the cross-section SEM images of the specimens corroded region are shown in Fig. 11. The black colour region represents the corroded area on the specimens. It can be observed that some $\beta$ phase residues are remaining in the corroded region implying the specimens are not 
uniform corroded. Near the uncorroded region boundary, some black dots are clearly observed in the $\alpha$ phase that are determined as corroded spots. This observation reveals that the pitting corrosion preferentially occurred at the $\alpha$ phase of the lamellar microstructure of EBM Ti6Al4V specimens, whereas the $\beta$ phase seems to be more resistant towards pitting corrosion. As such, the orientation pattern of the $\alpha+\beta$ lamellar structure may play a key role in the resistance against pitting corrosion. Since the SAA heat treated specimen has a very fine and well directional orientation, fig. 11(d) shows the corrosion region follows the Widmanstätten structure orientation. The transverse or diagonally Widmanstätten microstructure may impede the corrosion propagation. Therefore, the observation that the as printed specimen is the most susceptible to pitting corrosion (Table 4 ) is consistent with the narrow and discrete $\beta$ phase of the microstructure.
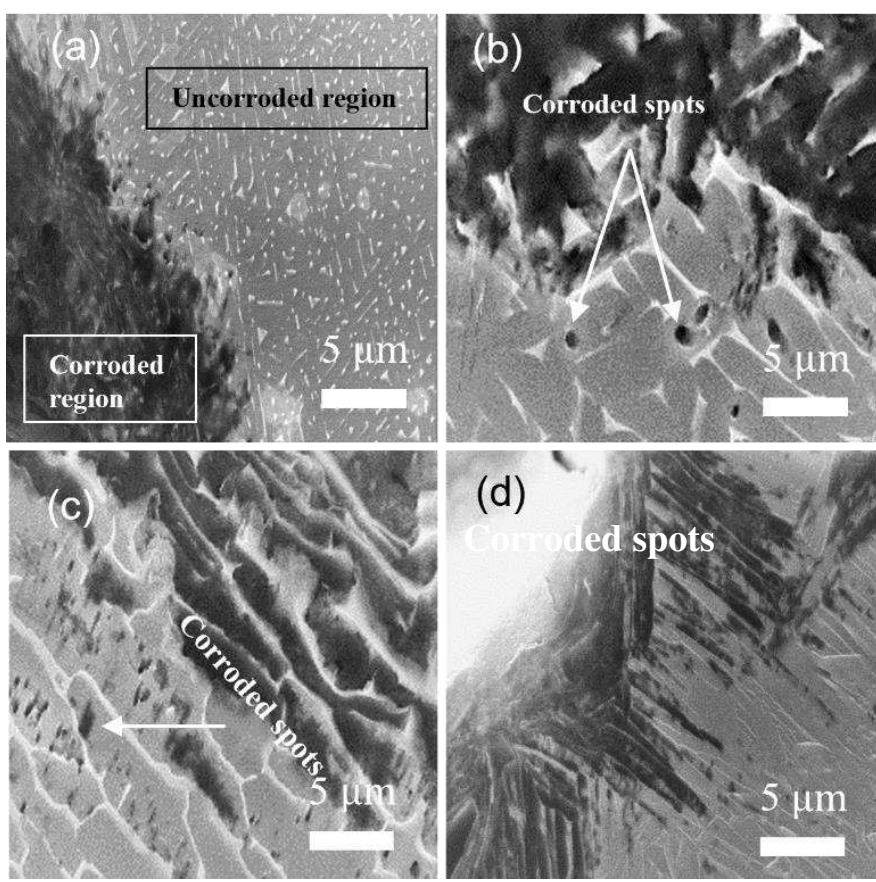

Fig. 11 SEM images of cross section view of corroded specimen: (a) as-printed, (b) sub $\beta$ transus, (c) super $\beta$-transus and (d) Solution Air-cooled \& Ageing (SAA)

\section{Discussion}

Based on the surface characterization and the microhardness testing, the different heat treatment conditions result in variation in the microstructure as well as mechanical property of electron beam melted (EBM) Ti6Al4V specimen. Fig. 12 presents the microhardness and $\alpha$ lath width of the EBM Ti6Al4V specimen. A clear trend is observed that an increase in the $\alpha$ lath width results in the decrease of microhardness. This result supports evidence from previous research in variation in constituent phases, size of prior $\beta$ grains, and $\alpha$ lath width would tailor the mechanical behaviours of AM Ti6Al4V $[4,19,38]$. All EBM specimens except the super $\beta$-transus show a better mechanical behaviour than the traditional processed Ti6Al4V. Since the $\alpha$ lath width varies with heating temperature and cooling rate, a fine microstructure and narrow $\alpha$ lath width of as printed specimen can be tailored through proper heat treatment. When the heating temperature is only above the $\beta$-transus temperature, the microstructure 
transformation will occur from the columnar morphology to the equiaxed structure. In particular, the fineness of the $\alpha+\beta$ lamellar within the equiaxed grains significantly depends on the cooling rate.

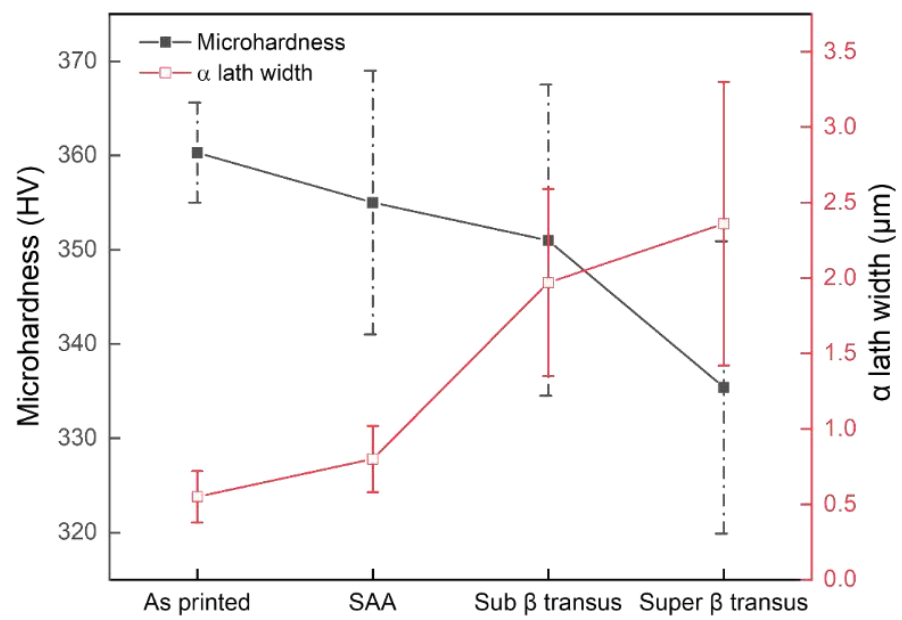

Fig. 12 Microhardness and $\alpha$ lath width for EBM specimens

The $\alpha$ lath width's effect on the electrochemical corrosion behaviour is investigated. Fig. 13 presents the relationship between the $\alpha$ lath width and pitting potential. From the as printed to SAA to sub $\beta$ transus and super $\beta$ transus, the $\alpha$ lath width increased while the pitting potential increased and then decreased slightly, i.e. the pitting potential does not have a positive linear relationship with the $\alpha$ lath width. In particular, the SAA sample had a much higher pitting potential similar to the sub $\beta$ transus and super $\beta$ transus samples while the $\alpha$ lath width of the SAA sample was only slightly higher than the as-printed sample. Hence the $\alpha$ lath width does not seem to be a good indicator of the pitting corrosion resistance.

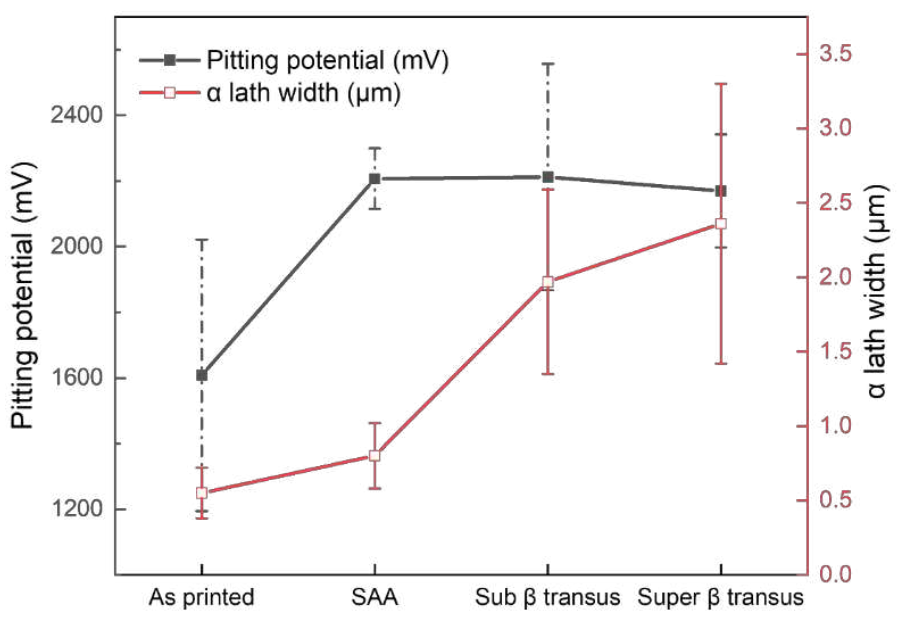

Fig. 13 Pitting potential and $\alpha$ lath width for EBM specimens

Fig. 14 shows the relationship between the pitting potential and the $\beta$ phase fraction. A general trend is observed that the pitting potential increases with an increase in the $\beta$ phase fraction. In contrast to the $\alpha$ lath width, the $\beta$ phase fraction seems to be a better indicator of the pitting corrosion resistance. The as printed EBM specimen has an inferior pitting potential as well as a low $\beta$ phase fraction. The higher $\beta$ phase 
fraction and the higher pitting potential are achieved through heat treatment. This finding is contrary to the previous study that Bai $\mathrm{Y}$ et al. found the as printed AM Ti6A4V had a better corrosion resistance due to higher $\beta$ phase fraction and the refined lamellar $\alpha+\beta$ phase gave a better corrosion resistance [24]. Selective corrosion in $\alpha$ $+\beta$ lamellar structure (Fig. 11) demonstrates that the $\alpha$ phase is more susceptible to pitting corrosion while the $\beta$ phase is nobler. The SEM-EDS data demonstrates that the $\beta$ phase is enriched with vanadium ( $\beta$ phase stabilizer). This outcome broadly supports the work of other studies in corrosion, adding the vanadium in the metal alloy was proven to have a positive effect in pitting and crevice corrosion resistance that reflected in the pitting potential $[39,40]$. It is reasonable to conclude the major factor that contributes to EBM Ti6Al4V corrosion resistance is the amount of $\beta$ phase present in the $\alpha+\beta$ lamellar structure.

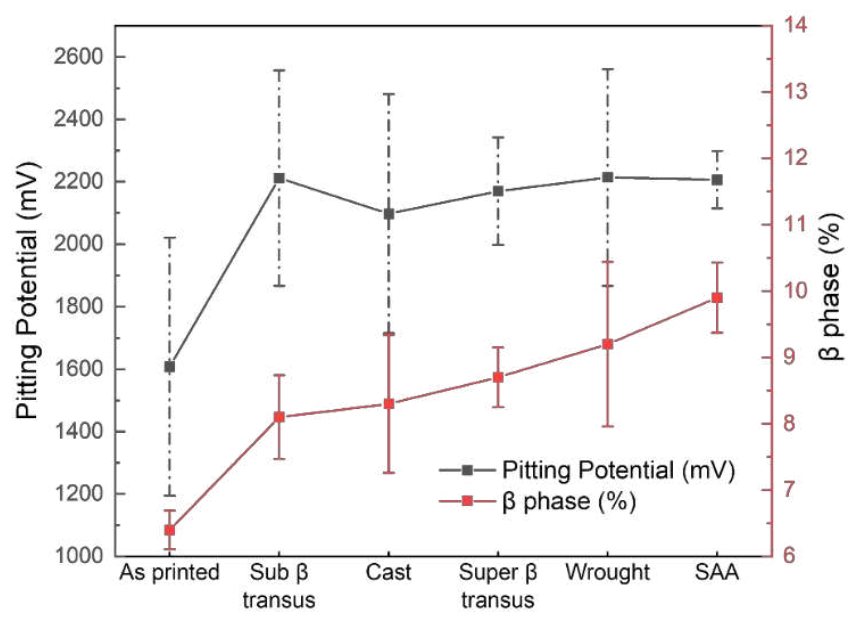

Fig. 14 Pitting potential and $\beta$ phase fraction for EBM Ti6Al4V specimens

Interestingly, the sub $\beta$-transus specimen has the best pitting corrosion resistance without the highest $\beta$ phase fraction. One possibility is that there may be a critical beta phase amount, possibly around $8 \%$, beyond which the pitting potential is maximized and will not be improved further with increasing beta fraction. Apart from the $\beta$ phase fraction effect, another feature of microstructure that can influence the electrochemical corrosion activities of EBM Ti6A14V is the $\alpha+\beta$ lamellar pattern. Since different features of the lamellar structure are obtained through three different heat treatments, the compactness and directional orientation of the lamellar structure may have an effect on the pitting corrosion resistance. SAA is identified to be the best heat treatment profile in this study for improving both the mechanical properties and corrosion resistance of EBM T6Al4V, because it has a high $\beta$ phase fraction (enhances pitting corrosion resistance) and a low $\alpha$ lath width (enhances the microhardness), comparable or better than that of the traditional cast and wrought processed Ti6Al4V metal alloy. Overall, these results indicate that SAA heat treatment is suitable for applications requiring both good corrosion resistance and good mechanical properties. 


\section{Conclusions}

This paper has investigated and compared the relationship in between the mechanical, the electrochemical behaviour and the microstructure of the electron beam melted (EBM) and post processed Ti6Al4V.

- As printed EBM Ti6Al4V has a columnar gain structure with very fine $\alpha+\beta$ lamellar phase. It exhibits an inferior electrochemical corrosion resistance. The heat treatment is an effective way to tailor the microstructure, and thus to enhance the mechanical properties and corrosion resistance.

- Microstructure transformation from columnar to equiaxed grains only occurs above the $\beta$-transus temperature. Thus, sub $\beta$-transus specimen has columnar structure whereas super $\beta$-transus and solution \& air-cooled specimens have an equiaxed structure. The $\alpha$ lath width is dependent on the heating temperature and cooling rate. Decreasing the $\alpha$ lath width will increase the microhardness.

- The heat treated EBM Ti6Al4V specimens exhibit a significant improvement in corrosion resistance. For pitting corrosion resistance, the $\beta$ phase fraction is a better indicator than the $\alpha$ lath width. The $\beta$ phase is more resistant to pitting corrosion due to the enrichment in vanadium. The compactness and orientation of $\alpha+\beta$ lamellar can be other potential factors affecting pitting corrosion.

- The solution air-cooled \& ageing heat treatment method is identified as the best heat treatment profile in this study for improving both the mechanical properties and corrosion resistance of as printed EBM Ti6Al4V metal part.

\section{Acknowledgements}

The authors acknowledge the support provided by Nanyang Technological University (NTU) and Singapore Institute of Manufacturing Technology (SIMTech). The work was financially supported by A*STAR Industrial Additive Manufacturing Program: Work Package 3 (Electron Beam Melting, Grant No. 1325504103).

Author contribution Mingzhen Xiu: conceptualization, experiment, data curation, writing of original draft and editing. Yong Teck Tan: supervision, data curation, review and editing. Srinivasan Raghavan: supervision, review and editing. Min Hao Goh: data curation. Mui Ling Sharon Nai: review, project administration and funding acquisition.

\section{Compliance with Ethical Standards}

Ethical approval Not applicable.

Date Availability We confirm that data is open and transparent

Competing interests The authors declare no competing interests. 


\section{References}

1. Harris Ian D (2017) Development and implementation of metals additive manufacturing. Additive Manufacturing Handbook, pp 215-224.

2. Srinivasan R, Mui Ling Sharon Nai, Pan W, Wai Jack S, Tao L, Jun W (2018) Heat treatment of electron beam melted (EBM) Ti-6Al-4V: microstructure to mechanical property correlations. Rapid Prototyp J 24: 774783. https://doi.org/10.1108/RPJ-05-2016-0070.

3. Stéphane G, Christopher H, Mohamed G, Rajarshi B (2017) Additive manufacturing of metals: a brief review of the characteristic microstructures and properties of steels, Ti-6Al-4V and high-entropy alloys. Sci Technol Adv Mater 18: 584-610. https://doi.org/10.1080/14686996.2017.1361305.

4. Shunyu L, Yung C S (2019) Additive manufacturing of Ti6Al4V alloy: A review. MATER DESIGN 164: 107552. https://doi.org/10.1016/ j.matdes.2018.107552.

5. N Kazantseva, P Krakhmalev, M Thuvander, I Yadroitsev, N Vinogradova, I Ezhov (2018) Martensitic transformations in Ti-6Al-4V (ELI) alloy manufactured by 3D Printing. Mater Charact 146: 101-112. https://doi.org/10.1016/j.matchar.2018.09.042.

6. O L A Harrysson, D R Cormier, D J Marcellin-Little, K R Jajal (2006) Direct fabrication of custom orthopedic implants using electron beam melting technology. Int J Adv Manuf Technol 193-208. http://dx.doi.org/10.26153/tsw/5604.

7. Xipeng T, Yihong K, Shu Beng T, Chee Kai C (2014) Application of electron beam melting (EBM) in additive manufacturing of an impeller. Proc of the Int Conf on Prog in Addit Manuf 327-332. https://doi.org/10.3850/978-981-09-0446-3_076.

8. Pan W, Xipeng T, Mui Ling Sharon Nai, Shu Beng T, Jun W (2016) Spatial and geometrical-based characterization of microstructure and microhardness for an electron beam melted Ti-6Al-4V component. MATER DESIGN 95: 287-295. https://doi.org/10.1016/j.matdes.2016.01.093.

9. Pan W, Mui Ling Sharon Nai, Xipeng T, Guglielmo V, Srinivasan R, Wai Jack S, Shu Beng T, Qing Xiang P, Jun W (2016) Recent progress of additive manufactured Ti-6Al-4V by electron beam melting. 26th Annual International Solid Freeform Fabrication Symposium-An Additive Manufacturing Conference 8-10, Austin, TX, USA.

10. Pan W, Mui Ling Sharon Nai, Wai Jack S, Jun W (2015) Effect of building height on microstructure and mechanical properties of big-sized Ti-6Al-4V plate fabricated by electron beam melting. MATEC web of conferences EDP Sciences 30-02001. https://doi.org/10.1051/matecconf/20153002001.

11. AA Antonysamy, J Meyer, P B Prangnell (2013) Effect of build geometry on the $\beta$-grain structure and texture in additive manufacture of Ti6Al4V by selective electron beam melting. Mater Charact 84: 153-168. https://doi.org/10.1016/j.matchar.2013.07.012.

12. Xipeng T, Yihong K, Yu Jun T, Marion D, Dominique M, Shu Beng T, Kah Fai L, Chee Kai C (2015) Graded microstructure and mechanical properties 
of additive manufactured Ti-6Al-4V via electron beam melting. Acta Mater 97: 1-16. https://doi.org/10.1016/j.actamat.2015.06.036.

13. Al-Bermani S S, M L Blackmore, Zhang W, I Todd (2010) The origin of microstructural diversity, texture, and mechanical properties in electron beam melted Ti-6Al-4V. Metall Mater Trans A Phys Metall Mater Sci 41: 34223434. http://dx.doi.org/10.1007/s11661-010-0397-x.

14. Facchini L, Emanuele M, Pierfrancesco R, Alberto M (2009) Microstructure and mechanical properties of $\mathrm{Ti}-6 \mathrm{Al}-4 \mathrm{~V}$ produced by electron beam melting of pre-alloyed powders. Rapid Prototyp J 15 (3) : 171-178.

https://doi.org/10.1108/13552540910960262.

15. Wei Quan T, Pan W, Xipeng T, Mui Ling Sharon Nai, Erjia L, Shu Beng T (2016) Microstructure and wear properties of electron beam melted Ti-6Al4V parts: A comparison study against as-cast form. Metals 6: 284. https://doi.org/10.3390/met6110284.

16. L E Murr, E V Esquivel, S A Quinones, S M Gaytan, M I Lopez, E Y Martinez, F Medina, D H Hernandez, E Martinez, J L Martinez, S W Stafford (2009) Microstructures and mechanical properties of electron beam-rapid manufactured $\mathrm{Ti}-6 \mathrm{Al}-4 \mathrm{~V}$ biomedical prototypes compared to wrought $\mathrm{Ti}-$ 6Al-4V. Mater Charact 60: 96-105. https://doi.org/10.1016/j.matchar.2008.07.006.

17. Xiaoli Z, Shujun L, Man Z, Yandong L, Timothy B Sercombe, Shaogang W, Yulin H, Rui Y, Lawrence E Murr (2016) Comparison of the microstructures and mechanical properties of $\mathrm{Ti}-6 \mathrm{Al}-4 \mathrm{~V}$ fabricated by selective laser melting and electron beam melting. MATER DESIGN 95: 21-31. https://doi.org/10.1016/j.matdes.2015.12.135.

18. Choi Y, Dong-Geun L (2019) Correlation between surface tension and fatigue properties of Ti-6Al-4V alloy fabricated by EBM additive manufacturing. APPL SURF SCI 481: 741-746. https://doi.org/10.1016/j.apsusc.2019.03.0993.

19. Galarraga H, Robert J Warren, Diana A Lados, Ryan R Dehoff, Michael M Kirka, Peeyush N (2017) Effects of heat treatments on microstructure and properties of Ti-6Al-4V ELI alloy fabricated by electron beam melting (EBM). Mater Sci Eng 685: 417-428. https://doi.org/10.1016/j.msea.2017.01.019.

20. Kiel-Jamrozik M, W Jamrozik, I Witkowska (2017) The heat treatment influence on the structure and mechanical properties of Ti6Al4V alloy manufactured by SLM technology. Conference on Innovations in Biomedical Engineering Springer 319-327. https://doi.org/10.1007/978-3-319-700632_34.

21. Nianwei D, Lai-Chang Z, Junxi Z, Xin Z, Qingzhao N, Yang C, Maoliang W, Chao Y (2016) Distinction in corrosion resistance of selective laser melted Ti-6Al-4V alloy on different planes. Corrosion Science 111: 703-710. https://doi.org/10.1016/j.corsci.2016.06.009.

22. Nianwei D, Lai-Chang Z, Junxi Z, Qimeng C, Maoliang W (2016) Corrosion behavior of selective laser melted Ti-6Al-4 $\mathrm{V}$ alloy in $\mathrm{NaCl}$ solution. Corrosion Science 102: 484-489. https://doi.org/10.1016/j.corsci.2015.10.041. 
23. Xiaojuan G, Yujie C, Daixiu W, Bin L, Ruiping L, Yan N, Yunping L (2017) Building direction dependence of corrosion resistance property of Ti-6Al-4V alloy fabricated by electron beam melting. Corrosion Science 127: 101-109. https://doi.org/10.1016/j.corsci.2017.08.008.

24. Bai Y, Gai X, Li S, Zhang L C, Liu Y, Hao Y, Zhang X, Yang R, Gao Y (2017) Improved corrosion behaviour of electron beam melted Ti-6Al-4V alloy in phosphate buffered saline. Corrosion Science 123: 289-296. https://doi.org/10.1016/j.corsci.2017.05.003.

25. Yangzi X, Yuan L, Kristin L Sundberg, Jianyu L, Richard D Sisson (2017) Effect of annealing treatments on the microstructure, mechanical properties and corrosion behavior of direct metal laser sintered Ti-6Al-4V. J Mater Eng Perform 26: 2572-2582. https://doi.org/10.1007/s11665-017-2710-y.

26. Jingjing Y, Huihui Y, Hanchen Y, Zemin W, Xiaoyan Z (2017) Corrosion behavior of additive manufactured Ti-6Al-4V alloy in $\mathrm{NaCl}$ solution. Metall Mater Trans A Phys Metall Mater Sci 48: 3583-3593. https://doi.org/10.1007/s11661-017-4087-9.

27. Abdeen D H, B R Palmer (2016) Corrosion evaluation of Ti-6Al-4V parts produced with electron beam melting machine. Rapid Prototyp J 22 (2) 322329. https://doi.org/10.1108/RPJ-09-2014-0104.

28. Gai Xin, Yun Bai, Ji Li, Shujun Li, Wentao Hou, Yulin H, Xing Z, Rui Y, R D K Misra (2018) Electrochemical behaviour of passive film formed on the surface of Ti-6Al-4V alloys fabricated by electron beam melting. Corrosion Science 145: 80-89. https://doi.org/10.1016/j.corsci.2018.09.010.

29. Kawalec Jill S, Stanley A Brown, Joe H Payer, Katharine Merritt (1995) Mixed-metal fretting corrosion of Ti6Al4V and wrought cobalt alloy. J Biomed Mater Res 29: 867-873. https://doi.org/10.1002/jbm.820290712.

30. A M Schmidt, D S Azambuja (2006) Electrochemical behavior of Ti and Ti6Al4V in aqueous solutions of citric acid containing halides. Materials Research 9: 387-392. https://doi.org/10.1590/S1516-14392006000400008.

31. Prando Davide, Andrea Brenna, Maria Vittoria Diamanti, Silvia Beretta, Fabio Bolzoni, Marco Ormellese, MariaPia Pedeferri (2017) Corrosion of titanium: Part 1: Aggressive environments and main forms of degradation. J Appl Biomater Funct Mater 15: 291-302. https://doi.org/10.5301\%2Fjabfm.5000387.

32. Huo S, Meng X (1990) The states of bromide on titanium surface prior to pit initiation. Corrosion science 31: 281-286. https://doi.org/10.1016/0010938X(90)90120-T.

33. Pahlavan S, Moayed M H, Mirjalili M (2019) The contrast between the pitting corrosion of $316 \mathrm{SS}$ in $\mathrm{NaCl}$ and $\mathrm{NaBr}$ solutions: Part I. Evolution of metastable pitting and stable pitting. J Electrochem Soc 166: 65. http://dx.doi.org/10.1149/2.0811902jes.

34. Popov V, Katz-Demyanetz A, Garkun A, Muller G, Strokin E, Rosenson H (2018) Effect of hot isostatic pressure treatment on the electron-beam melted Ti-6Al-4V specimens. Procedia Manuf 21: 125-132. https://doi.org/10.1016/j.promfg.2018.02.102.

35. S L Semiatin, S L Knisley, P N Fagin, D R Barker, F Zhang (2003) Microstructure evolution during alpha-beta heat treatment of Ti-6Al-4V. 
Metallurgical and Materials Transactions A 34: 2377-2386.

https://doi.org/10.1007/s11661-003-0300-0.

36. Safdar A, L Y Wei, Anders Snis, Zhonge Lai (2012) Evaluation of microstructural development in electron beam melted Ti-6Al-4V.

Mater Charact 65: 8-15. https://doi.org/10.1016/j.matchar.2011.12.008.

37. Kumar Kurnala Naresh, Pravin Muneshwar, Satish Kumar Singh, Abhay K Jha, Bhanu Pant, Koshy M George (2015) Effect of grain boundary alpha on mechanical properties of Ti5. 4Al3Mo1V alloy. JOM 67: 1265-1272. https://doi.org/10.1007/s11837-015-1443-3.

38. Lütjering G E R D (1998) Influence of processing on microstructure and mechanical properties of $(\alpha+\beta)$ titanium alloys. Mater Sci Eng A 243: 32-45. https://doi.org/10.1016/S0921-5093(97)00778-8.

39. M H Ras, P C Pistorius (2002) Possible mechanisms for the improvement by vanadium of the pitting corrosion resistance of $18 \%$ chromium ferritic stainless steel. Corrosion science 44: 2479-2490. https://doi.org/10.1016/S0010-938X(02)00050-1.

40. Sherif E S M, Abdo H S, Alharthi N H (2020) Beneficial Effects of Vanadium Additions on the Corrosion of Ti6AlxV Alloys in Chloride Solutions. Metals 10: 264. https://doi.org/10.3390/met10020264. 